Check for updates

Cite this: RSC Adv., 2017, 7, 46060

\title{
Preparation and microwave absorbing property of carbon fiber/polyurethane radar absorbing coating
}

\author{
Zhao-hui Liu, ${ }^{a}$ Rui Tao, (D) *a Ping Luo, ${ }^{a}$ Xin Shu ${ }^{a}$ and Guo-dong Ban ${ }^{b}$
}

To broaden the effective absorbing bandwidth of radar absorbing coating, carbon fiber/polyurethane radar absorbing coating (CFPURAC) is prepared with carbon fiber as filler and polyurethane as matrix, and then multi-layer CFPURAC is prepared with polyurethane coating as wave-transmitting material to match CFPURAC. Scanning electron microscope (SEM) and metallography microscope are employed to characterize the microstructure of filler and coating separately. Vector network analyzer (VNA) is adopted to test the radar wave reflectivity of coating. The results indicate that the absorbing property of coating is influenced by length and content of carbon fiber in the coating, and matching order and matching thickness of various absorbing layers to a great extent. In the optimum matching proposal, the effective absorbing bandwidth of coating is up to $13.1 \mathrm{GHz}$, and an effective absorption can be achieved within the range of $4.9 \mathrm{GHz}$ to $18 \mathrm{GHz}$.

Received 12th July 2017

Accepted 14th September 2017

DOI: $10.1039 / \mathrm{c} 7 \mathrm{ra07666e}$

rsc.li/rsc-advances

the matching thickness of carbon fiber on coating absorbing property.

\section{Introduction}

As an important way to realize radar stealth technique, radar absorbing coating is of good effect, simple process, easy design and low cost, making it a critical technology to improve the stealth performance of equipment and a significant role in radar stealth technique. ${ }^{1,2}$ Recently all sorts of novel aircrafts and ships make use of radar absorbing coating extensively to enhance their anti-reconnaissance ability. ${ }^{3}$

The application of short carbon fiber to absorbing coating as filling brings about many merits such as light weight, high strength and small addition, and figures out an important way how to develop radar absorbing coating. ${ }^{4-6}$ Nevertheless, carbon fiber is characterized with a bigger electrical conductivity, so its addition to coating should not be too high. Otherwise continuous conductive network is likely to form and reflect most of electromagnetic wave, and therefore the absorbing property of carbon fiber is refrained. In the majority of current studies, the absorbing property of carbon fiber is enhanced by activating treatment of carbon fiber, ${ }^{7,8}$ or modifying treatment of carbon fiber with nanometer iron powder, ${ }^{9}$ nickalloy, ${ }^{10}$ carbonyl iron powder ${ }^{11}$ and other materials while there are fewer studies on multi-layer matching radar absorbing coating which is prepared with carbon fiber radar absorbing coating as matrix.

In this paper, radar absorbing coating is prepared with radar short carbon fiber as absorbent and waterborne polyurethane as matrix resin, and then wave-transmitting layers are matched to systematically analyze the impact of the content, the length, and

${ }^{a}$ Dept. of Chemistry \& Material Engineering, Logistic Engineering University of PLA, Chongqing, 401311, China.E-mail: itaorui@163.com

${ }^{b}$ Unit 75752 of PLA, Guangdong 517000, China

\section{Experiment}

\subsection{Materials}

Polyurethane (PU) was Bayhydrol2648 waterborne polyurethane supplied by Yuanhe Chemical Co., Ltd. Shanghai China (nonvolatile content: $34-36 \%$; density: $1.07 \mathrm{~g} \mathrm{ml}^{-1}$ ). Carbon fiber (CF) was the LS-CF-S carbon fiber purchased from Liso Composite Material Technology Co., Ltd. Shanghai China (tensile strength: $4900 \mathrm{MPa}$; tensile modulus: $230 \mathrm{GPa}$; elongation: $2.1 \%$; density: $1.80 \mathrm{~g} \mathrm{~cm}^{3}$ ). Thickening agent was RM-8W thickening agent bought from Hongrun Chemical Co., Ltd., Guangzhou, China (nonvolatile content: 20.8-21.8\%; density: $1.04 \mathrm{~g} \mathrm{ml}^{-1}$ ). Defoaming agent was BYK011 waterborne defoaming agent purchased from Sunny Chemicals Ltd., H. K., China (nonvolatile content: $29 \%$; density: $0.8 \mathrm{~g} \mathrm{ml}^{-1}$ ).

\subsection{Sample preparation}

$\mathrm{PU}$ and $\mathrm{CF}$ were prepared by a fixed mass proportion. Then the $0.5 \mathrm{wt} \%$ thickening agent was added into the PU which was later processed with a disperser (SF smart dispersing sand mill) at the speed of 300 RPM for $10 \mathrm{~min}$. After the thickening, the filler was put into the resin that was also dispersed at the same speed for $30 \mathrm{~min}$. When uniformly dispersed, the mixture was placed into a mold by a fixed thickness. The curing process first proceeded at room temperature for 12 hours, then in oven by $50^{\circ} \mathrm{C}$ for 24 hours.

\subsection{Testing}

The microscopic morphology of CF was characterized with a scanning electron microscope (HITACHI-S3700N SEM, 
Hitachi Co., Ltd., Tokyo, Japan). The SEM was operated at an accelerating voltage of $15 \mathrm{kV}$.

The phase analyses of CF was observed with a diffraction analyzer (DX-2700 X-ray, Fangyuan Instrument Co., Ltd., Dandong, China) with a working voltage of $35 \mathrm{kV}$ and a working current of $25 \mathrm{~mA}$. The step width was $0.02^{\circ}$.

The vector network analyzer (PNA E8363B vector network analyzer, Agilent Technologies Inc., California, USA) was used through NRL-arc method to test the reflectivity of electromagnetic wave (EM wave) in the $2-18 \mathrm{GHz}$ frequency range at room temperature.

\section{Results and conclusions}

\subsection{Microscopic morphology analysis}

Fig. 1 indicates that the SEM image of CF. According to the image, the $\mathrm{CF}$ has a filamentous structure with an average diameter of $7 \mu \mathrm{m}$, and there are several small grooves on the surface which are beneficial to the combination of $\mathrm{CF}$ and matrix resin.

Fig. 2 indicates that the metallurgical microscope image of CFPURAC. According to the image, the length of CFs exist certain difference for sake of the different gradient of $\mathrm{CF}$ in CFPURAC, but the CFs are randomly distributed in the matrix resin along different directions without obvious entanglement and reunion, and the spacing between CFs is relatively even.

\subsection{XRD measurements of CF}

The XRD spectra of CF was shown in Fig. 3. An obvious peak appeared in $25^{\circ}$, which corresponded to the (002) crystal plane of the graphite structure, while the (110) crystal plane $\left(44^{\circ}\right)$ and (112) crystal plane $\left(83^{\circ}\right)$ of the graphite structure is not obvious, which indicated that the $\mathrm{CF}$ is a non-graphitized carbonaceous structure.

\subsection{Analysis of complex permittivity}

Fig. 4 shows the complex permittivity of PU and the compound of CF and PU. Fig. 4(a) presents that the real part of complex permittivity $\left(\varepsilon^{\prime}\right)$ of PU was no more than 2.8 which means the reflection of PU on microwave is weaker, and the imaginary part

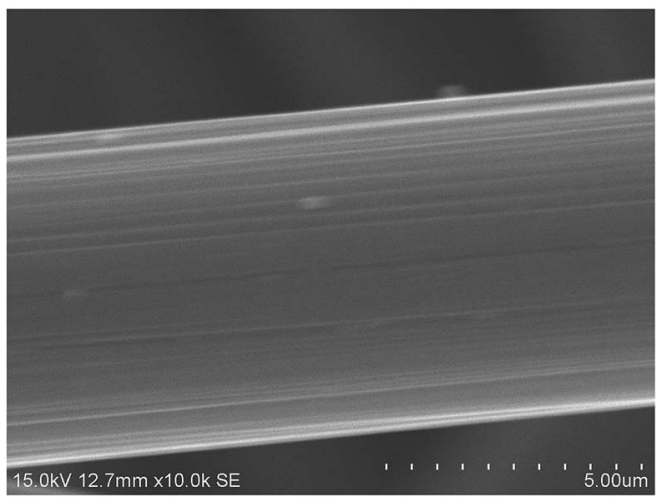

Fig. 1 SEM image of CF.

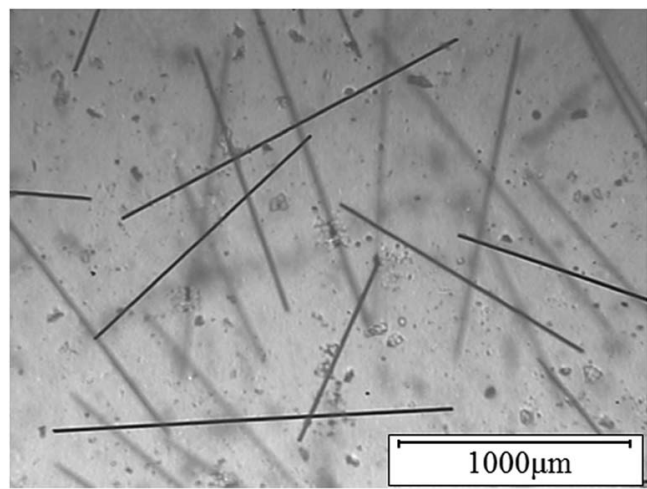

Fig. 2 Metallurgical microscope image of CFPURAC.

of complex permittivity $\left(\varepsilon^{\prime \prime}\right)$ of PU was close to 0 , indicating the PU almost does not consume microwaves. Fig. 4(a) presents that the real part and the imaginary part of complex permittivity both increased after CF was added to PU, as the frequency goes up from $2 \mathrm{GHz}$ to $18 \mathrm{GHz}$, the real part of complex permittivity dropped from 10.3 to 5.8 and the imaginary part of complex permittivity rose from 1.1 to 4.6 , which indicates the compound of CF and PU have the frequency response effect.

\subsection{Absorbing property of double-layer CFPURAC}

Single-layer CFPURAC just contains a small number of short CF, leading to smaller permittivity and dielectric loss tangent, so the absorbing property is very weak while it is used alone. According to general matching law and transmission line theory, after the matching of single-layer absorbing coating and wave-transmitting material, reflection factor of complex coating can be expressed as: ${ }^{12}$

$$
R=\frac{Z_{\text {in }}-Z_{0}}{Z_{\text {in }}+Z_{0}}
$$

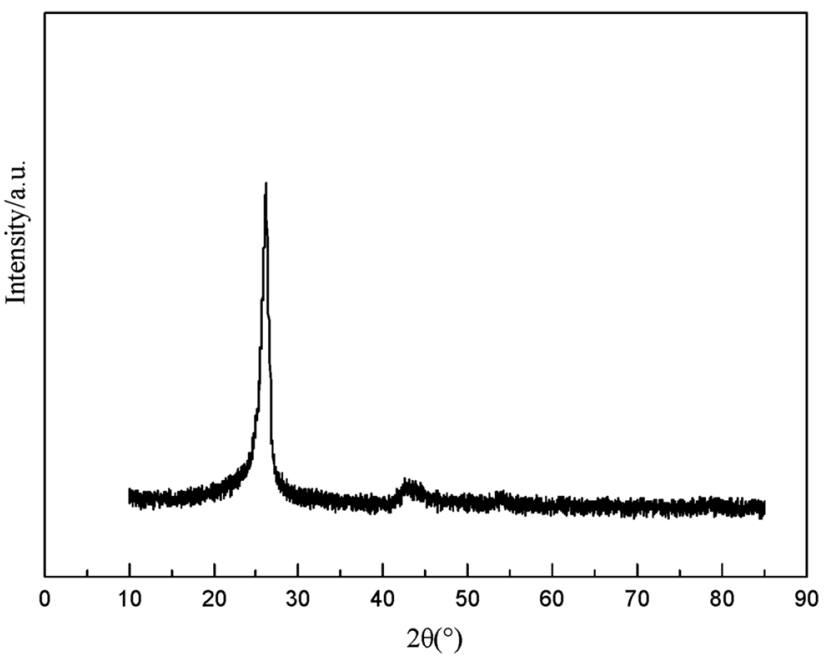

Fig. 3 The XRD spectra of CF. 


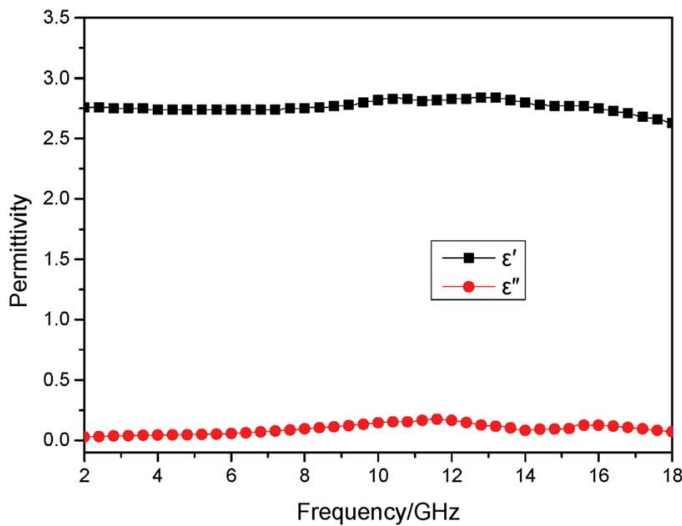

(a) $\mathrm{PU}$

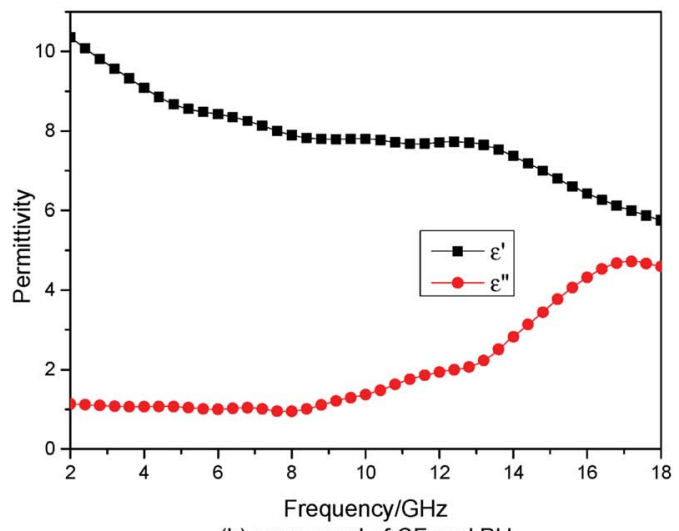

(b) compound of $\mathrm{CF}$ and $\mathrm{PU}$

Fig. 4 Complex permittivity of PU and the compound of CF and PU.

$$
Z_{\text {in }}=\frac{j Z_{1} Z_{2} \tan \left[\gamma_{1} d_{1}+\gamma_{2} d_{2}\right]}{Z_{1}+j Z_{2} \tan \left[\gamma_{1} d_{1}+\gamma_{2} d_{2}\right]}
$$

In eqn (1) and (2), $Z_{\text {in }}$ means equivalent input impedance of complex coating; $Z_{0}$ means input impedance of free space; $Z_{1}$ means characteristic impedance of $\mathrm{CF}$ coating; $Z_{2}$ means transmission line characteristic impedance; $d_{1}$ means thickness of single-layer absorbing coating; $d_{2}$ means thickness of wavetransmitting material; $\gamma_{1}, \gamma_{2}$ means propagation constant, which can be expressed: $\gamma=\alpha+j \beta$. $\alpha$ and $\beta$ represent attenuation factor and phase factor individually:

$$
\alpha=\frac{\omega \sqrt{\mu^{\prime} \varepsilon^{\prime}}}{c} \sqrt{1 / 2\left[\operatorname{tg} \delta_{\mathrm{e}} \operatorname{tg} \delta_{\mathrm{m}}-1+\sqrt{\left(1+\operatorname{tg}^{2} \delta_{\mathrm{e}}\right)\left(1+\operatorname{tg}^{2} \delta_{\mathrm{m}}\right)}\right]}
$$

$$
\beta=\frac{\omega \sqrt{\mu^{\prime} \varepsilon^{\prime}}}{c} \sqrt{1 / 2\left[1-\operatorname{tg} \delta_{\mathrm{e}} \operatorname{tg} \delta_{\mathrm{m}}+\sqrt{\left(1+\operatorname{tg}^{2} \delta_{\mathrm{e}}\right)\left(1+\operatorname{tg}^{2} \delta_{\mathrm{m}}\right)}\right]}
$$

In eqn (3) and (4), $\operatorname{tg} \delta_{\mathrm{e}}=\frac{\varepsilon^{\prime \prime}}{\varepsilon^{\prime}}$ and $\operatorname{tg} \delta_{\mathrm{m}}=\frac{\mu^{\prime \prime}}{\mu^{\prime}}$ stand for dielectric loss tangent and magnetic loss tangent separately, and $d=\lambda / 4=\pi / 2 \beta=\pi / 2 \beta_{1}+\pi / 2 \beta_{2}$ under the optimum matching condition. ${ }^{13}$

Eqn (1)-(4) indicate that matching PUCFAC with wavetransmitting material can effectively improve the absorbing property of coating.

According to the radar absorbing coating's reflecting and absorbing model, when the microwave $\left(E_{\mathrm{i}}\right)$ reached the coating's front surface, part of the microwave $\left(E_{\mathrm{r}}\right)$ would be reflected back into the air by the surface, the other part $\left(E_{\mathrm{t}}\right)$ would penetrate into the coating. After going through consumption process by the coating, the leftover microwave $\left(E_{\mathrm{e}}\right)$ would be reflected back into the air. If the consumed microwave is assumed to be $E_{1}$, then the entire process will be like Fig. 5 .

The energy relations in Fig. 5 are $E_{\mathrm{i}}=E_{\mathrm{r}}+E_{\mathrm{t}}$ and $E_{\mathrm{t}}=E_{\mathrm{l}}+E_{\mathrm{e}}$. If $E_{\mathrm{r}}$ and $E_{\mathrm{e}}$ have equal or very nearly equal amplitudes and opposite phase, we see the destructive interference with $E_{\mathrm{r}}$ and $E_{\mathrm{e}}$. For double-layer CFPURAC, the amplitude of $E_{\mathrm{r}}$ and $E_{\mathrm{e}}$ can be controlled by adjusting the content and length of CF, while the phase difference between $E_{\mathrm{r}}$ and $E_{\mathrm{e}}$ can be controlled by adjusting the matching thickness at a certain frequency, to attain destructive interference and achieve good microwave absorption.

3.4.1 Impact of matching thickness on absorbing property. Test results show that polyurethane coating (PUC) is a good wave-transmitting material, so PUC is matched with CFPURAC to prepare double-layer CFPURAC. Fig. 6 is the matching diagram of double-layer CFPURAC, and the thickness of CFPURAC is $0.5 \mathrm{~mm}$.

Fig. 7 is reflectivity of double-layer CFPURAC (CF content: $0.03 \mathrm{wt} \%$ and length: $3 \mathrm{~mm}$ ) with different matching thickness (the thickness of PUC). During the transmission of microwave in the coating, the effective thickness becomes smaller with a lower frequency and a longer wave length. Accordingly, any change of effective thickness will cause the variance of matching conditions of interface impedance. As the frequency varies, there exists a peak for absorbing property. ${ }^{\mathbf{1 4}}$ Seen from Fig. 6, while the matching layer thickness increased from $0.5 \mathrm{~mm}$ to $3 \mathrm{~mm}$ gradually, the maximum absorption peak of complex coating moved from high frequency to low frequency bit by bit. In the S-band $(2-4 \mathrm{GHz})$ and $\mathrm{C}$-band (4-8 GHz), with the increase of matching thickness, coating reflectivity dropt

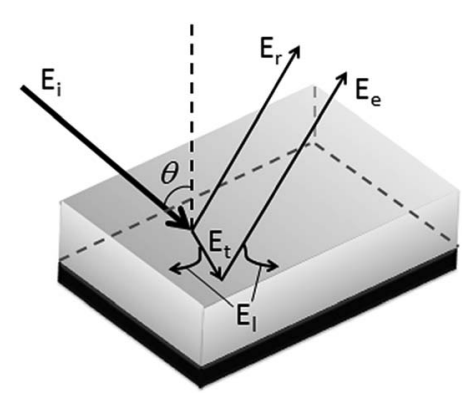

Fig. 5 Single layer penal radar absorbing coating's reflecting and absorbing model. 


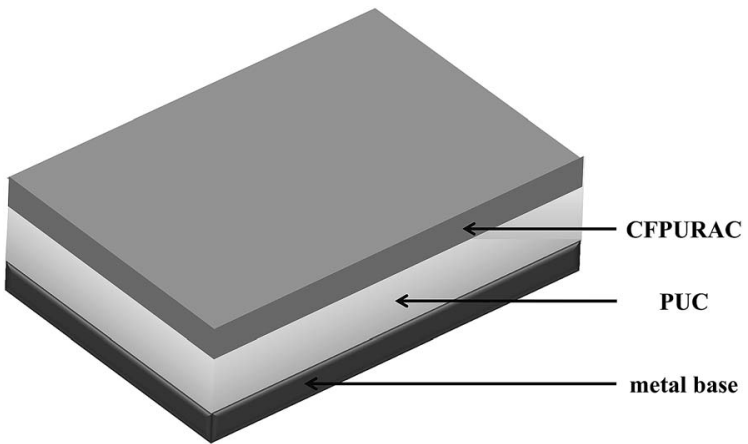

Fig. 6 Matching diagram of double-layer CFPURAC.

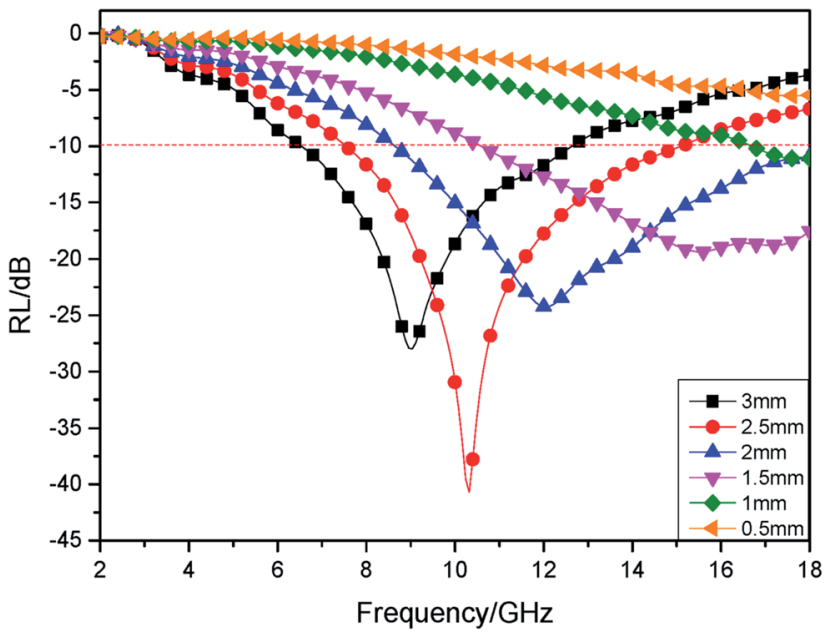

Fig. 7 Reflectivity of double-layer CFPURAC with different matching thicknesses.

gradually; when the matching thickness was same, reflectivity kept decreasing with the ascending of frequency. In the X-band $(8-12 \mathrm{GHz})$, the sudden change of coating reflectivity curve took place with the change of matching thickness. While the matching thickness was $2.5 \mathrm{~mm}$, reflectivity came to the minimum peak value, which was $-41 \mathrm{~dB}$ and reflectivity $<-10$ $\mathrm{dB}$ within the whole X-band. In the Ku-band (12-18 GHz), reflectivity fell first and then ascended with a minimum peak value of $-24.3 \mathrm{~dB}$, while the matching thickness increased. Once the matching thickness was $1.5 \mathrm{~mm}$ or $2 \mathrm{~mm}$, reflectivity within the whole Ku-band was $<-10 \mathrm{~dB}$. In $2-18 \mathrm{GHz}$, the minimum peak value reached the minimum $(-41 \mathrm{~dB})$ while the matching thickness was $2.5 \mathrm{~mm}$, the effective absorbing bandwidth (reflectivity $<-10 \mathrm{~dB}$ ) reached the maximum (8.6-18 $\mathrm{GHz}$ ) while the matching thickness was $2.5 \mathrm{~mm}$.

3.4.2 Impact of $\mathrm{CF}$ content on absorbing property. In accordance with transmission line theory, input impedance is closely related to permittivity of the PUCFRAC, and the CF content is one of the most important determinants of permittivity. ${ }^{15}$ Therefore, the change of CF content affects the absorbing property to a great extent. Fig. 8 indicates the reflectivity of double-layer CFPURAC with different CF contents (matching thickness: $2 \mathrm{~mm}$ and $\mathrm{CF}$ length: $3 \mathrm{~mm}$ ). The change

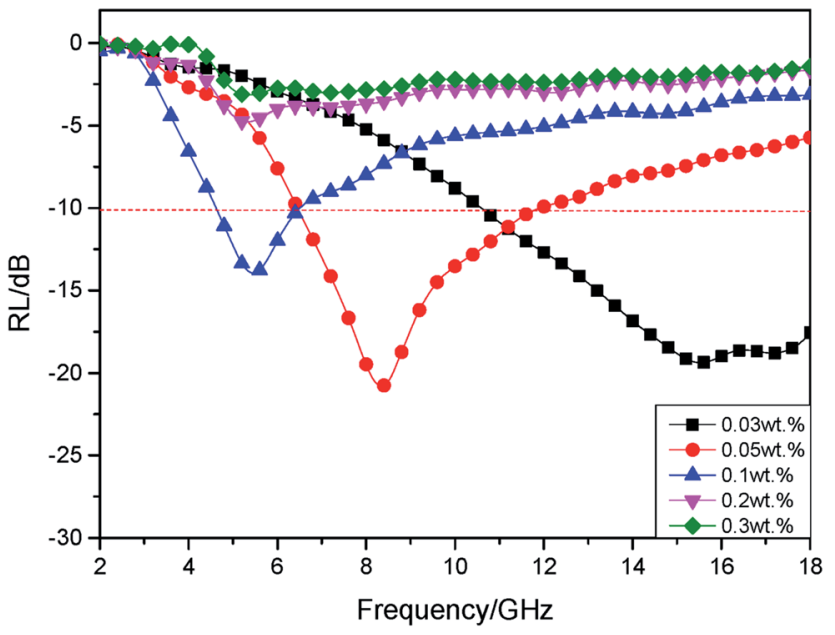

Fig. 8 Reflectivity of double-layer CFPURAC with different CF contents.

of CF content had an impact on the double-layer CFPURAC in terms of both absorbing strength and effective absorbing band. As CF content increased, the maximum absorbing peak moved to low frequency gradually, and when CF content was $0.03 \mathrm{wt} \%$, the maximum absorbing peak appeared in Ku-band. Once CF content reached $0.05 \mathrm{wt} \%$, the maximum absorbing peak appeared in X-band. While CF content was $0.1 \mathrm{wt} \%$, the maximum absorbing peak was observed in C-band. But when CF content exceeded $0.1 \mathrm{wt} \%$, there was no effective absorbing property ranging from $2 \mathrm{GHz}$ to $18 \mathrm{GHz}$.

Table 1 shows absorbing properties of double-layer CFPURAC with different CF contents (CF length is $3 \mathrm{~mm}$ ). Seen from the data in the table, although absorbing properties went through big changes under different matching thicknesses, the maximum absorbing peak frequency tended to decrease and the effective absorbing band moved to low

Table 1 Absorbing property of double-layer CFPURAC with different CF contents

\begin{tabular}{lllll}
\hline $\begin{array}{l}\text { Matched } \\
\text { thickness } \\
(\mathrm{mm})\end{array}$ & $\begin{array}{l}\text { Content } \\
\text { of CF }\end{array}$ & $\begin{array}{l}\text { Lowest } \\
\text { reflectivity } \\
(\mathrm{dB})\end{array}$ & $\begin{array}{l}\text { Frequency of } \\
\text { maximum } \\
\text { absorption }(\mathrm{GHz})\end{array}$ & $\begin{array}{l}\text { Effective } \\
\text { absorption } \\
\text { frequency }(\mathrm{GHz})\end{array}$ \\
\hline 1 & $0.03 \mathrm{wt} \%$ & 5.5 & 17.5 & - \\
& $0.05 \mathrm{wt} \%$ & 7.8 & 15.7 & - \\
& $0.1 \mathrm{wt} \%$ & 5.2 & 11.2 & - \\
& $0.2 \mathrm{wt} \%$ & 3.3 & 7.5 & - \\
2 & $0.3 \mathrm{wt} \%$ & 2.7 & 7.2 & - \\
& $0.03 \mathrm{wt} \%$ & 19.4 & 15.5 & $10.5-18$ \\
& $0.05 \mathrm{wt} \%$ & 20.8 & 8.3 & $6.5-11.9$ \\
& $0.1 \mathrm{wt} \%$ & 14 & 5.5 & $4.6-6.5$ \\
& $0.2 \mathrm{wt} \%$ & 4.7 & 5.3 & - \\
3 & $0.3 \mathrm{wt} \%$ & 3.1 & 5.2 & - \\
& $0.03 \mathrm{wt} \%$ & 41 & 10.3 & $5.5-15$ \\
& $0.05 \mathrm{wt} \%$ & 22 & 6.7 & $4.5-5.7$ \\
& $0.1 \mathrm{wt} \%$ & 13.2 & 5 & - \\
& $0.2 \mathrm{wt} \%$ & 3.9 & 4.8 & -
\end{tabular}


frequency when CF content went up. Once CF content was over $0.2 \mathrm{wt} \%$, the effective absorbing properties cannot be achieved, regardless of matching thickness. The increase of CF content results in a larger electron concentration around $\mathrm{CF}$ and a smaller gap between CFs. And then part of high-energy electrons could transcend surface potential barrier and generate electric current, which cause the increase of permittivity and the decrease of input impedance, making double-layer CFPURAC has a better matching performance at a low frequency. However, when CF content is excessive, permittivity keeps growing so as to cause the failure of impedance matching within 2 to 18 GHz. ${ }^{16,17}$

3.4.3 Impact of CF length on absorbing property. Fig. 9 is reflectivity of double-layer CFPURAC with different CF lengths (content: $0.1 \mathrm{wt} \%$ and matching thickness: $2 \mathrm{~mm}$ ). In the $\mathrm{S}$ band and the C-band, while CF length is $3 \mathrm{~mm}$, absorbing peak was the lowest and the effective absorbing bandwidth was the widest; in the X-band and the Ku-band, while CF length was $2 \mathrm{~mm}$, absorbing peak was the lowest and the effective absorbing bandwidth was the widest; while CF length was 1 $\mathrm{mm}$, double-layer CFPURAC lost an effective absorbing property at 2 to $18 \mathrm{GHz}$.

Table 2 shows absorbing properties of double-layer CFPURAC with different CF lengths (matching thickness is 2 $\mathrm{mm}$ ) under a certain fiber content. See from the date in the table, while CF length increased, the maximum absorbing peak and the effective absorbing band moved to low frequency. Once CF content was less than $0.1 \mathrm{wt} \%$, coating absorbing property was enhanced increasingly with the increase of CF length, but coating gained the effective absorbing property only when $\mathrm{CF}$ length was up to $3 \mathrm{~mm}$; when CF content was between $0.1 \mathrm{wt} \%$ and $0.2 \mathrm{wt} \%$, absorbing property first increased and then dropt with the increase of CF length, and the best absorbing property was observed once $\mathrm{CF}$ length gets to $2 \mathrm{~mm}$; in the case that $\mathrm{CF}$ content exceeded $0.2 \mathrm{wt} \%$, absorbing property dropt gradually with the increase of CF length, and double-layer CFPURAC already had a better absorbing property with $\mathrm{CF}$ which was $1 \mathrm{~mm}$ long. When CF content is lower, for shorter CF, there is an

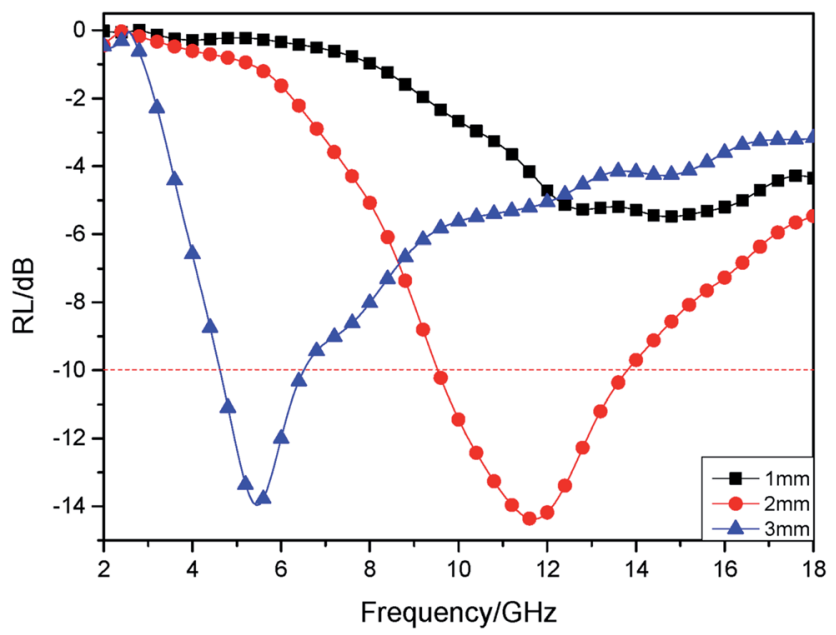

Fig. 9 Reflectivity of double-layer CFPURAC with different CF lengths. excessively short distance for induced current incurred by microwave to flow along fiber, which cannot act on microwave effectively. By enlarging the length of $\mathrm{CF}$, fiber draw ratio is increased and the ability of fiber to form the conductive network in matrix resin is enhanced. When CF content is higher, mutual contact of fibers in a smaller area increases the flow distance of induced current, but if fiber is too long at this point, it is likely to form a continuous conductive network inside coating and cause difficulties to microwave absorption. ${ }^{18}$

\subsection{Absorbing property of four-layer CFPURAC}

According to the analysis of 2.3, compared with single-layer PUCFAC, double-layer PUCFAC has a much better absorbing property, but in general, the effective absorbing bandwidth is narrower. Therefore, double-layer PUCFAC is sorted as high frequency absorbing layer and low frequency absorbing layer. Four-layer CFPURAC is prepared by matching high frequency absorbing layer with low frequency absorbing layer to broaden the effective absorbing bandwidth of coating. Table 3 and Table 4 individually present CF length and content of selected high frequency absorbing layer and low frequency absorbing layer.

3.5.1 Impact of absorbing layer sequence on absorbing property. The impact of absorbing layer sequence on absorbing property is studied with $\mathrm{H} 1$ as high frequency absorbing layer and L1 as low frequency absorbing layer under $2 \mathrm{~mm}$ of matching thickness. Fig. 10 shows radar wave reflectivity of two proposals. In proposal A, L1 was upper layer and H1 was lower, most of the high frequency microwave is reflected back into the air by low frequency absorbing layer; part of low frequency microwave could penetrate into the coating, but the total thickness of coating the matching was not appropriate to achieve good microwave absorption. In proposal B, H1 was upper layer and L1 was lower, the high frequency absorbing layer and the low frequency absorbing layer could both play a part in absorbing microwave, coating reflectivity reaches the peak at 6.3 $\mathrm{GHz}$ and $14.4 \mathrm{GHz}$ separately, and comes to $-10 \mathrm{~dB}$ at both 5.3 to $8.6 \mathrm{GHz}$ and 10.3 to $16.9 \mathrm{GHz}$.

It is learnt for analysis above that four-layer CFPURAC has a better overall absorbing property while high frequency absorbing layer is upper and low frequency absorbing layer is lower, and the matching diagram of four-layer CFPURAC is showed in Fig. 11, and the thickness of CFPURACs are $0.5 \mathrm{~mm}$.

3.5.2 Impact of high frequency absorbing layer on absorbing property. The impact of matching thicknesses of four high frequency absorbing layers including $\mathrm{H} 1, \mathrm{H} 2, \mathrm{H} 3$ and $\mathrm{H} 4$ on absorbing property is studied with L1 as low frequency absorbing layer, and the low frequency matching thickness (the thickness of PUC in low frequency absorbing layer) is fixed as 2 mm. Fig. 12 shows radar wave reflectivity of four-layer CFPURAC with different high frequency matching thickness (the thickness of PUC in high frequency absorbing layer) when $\mathrm{H} 1, \mathrm{H} 2$, $\mathrm{H} 3$ and $\mathrm{H} 4$ are regarded as high frequency absorbing layers. Seen from the Fig. 12, when high frequency matching thickness is $0.5 \mathrm{~mm}$, coating has the best absorbing property in the $\mathrm{C}$ band, but coating reflectivity is bigger than $-10 \mathrm{~dB}$ in both the X-band and the Ku-band; with the increase of matching 
Table 2 Absorbing property of Double-layer CFPURAC with different CF lengths

\begin{tabular}{|c|c|c|c|c|}
\hline $\begin{array}{l}\text { Content of } \\
\text { CF }(\mathrm{mm})\end{array}$ & $\begin{array}{l}\text { Length of } \\
\mathrm{CF}(\mathrm{mm})\end{array}$ & $\begin{array}{l}\text { Lowest reflectivity } \\
\text { (dB) }\end{array}$ & $\begin{array}{l}\text { Frequency of maximum } \\
\text { absorption }(\mathrm{GHz})\end{array}$ & $\begin{array}{l}\text { Effective absorption } \\
\text { frequency }(\mathrm{GHz})\end{array}$ \\
\hline \multirow{2}{*}{$0.03 \mathrm{wt} \%$} & 1 & -1.4 & 18 & - \\
\hline & 3 & -19.4 & 15.5 & $10.6-18$ \\
\hline \multirow[t]{2}{*}{0.05 wt $\%$} & 1 & -2.9 & 18 & - \\
\hline & 2 & -11.9 & 12.6 & $11.6-14.8$ \\
\hline & 2 & -14.4 & 11.7 & $9.6-13.8$ \\
\hline & 3 & -13.9 & 5.4 & $4.6-6.5$ \\
\hline \multirow[t]{3}{*}{$0.2 \mathrm{wt} \%$} & 1 & -13.9 & 14 & $12.1-16.1$ \\
\hline & 2 & -39.8 & 6.5 & $5.6-8.3$ \\
\hline & 3 & -4.8 & 5.3 & - \\
\hline 0.3 wt $\%$ & 1 & -38.4 & 11.4 & $9.8-13.9$ \\
\hline
\end{tabular}

Table 3 High frequency absorbing layer

\begin{tabular}{lllll}
\hline Serial Number & $\mathrm{H} 1$ & $\mathrm{H} 2$ & $\mathrm{H} 3$ & $\mathrm{H} 4$ \\
\hline CF Length & $1 \mathrm{~mm}$ & $1 \mathrm{~mm}$ & $2 \mathrm{~mm}$ & $2 \mathrm{~mm}$ \\
CF Content & $0.1 \mathrm{wt} \%$ & $0.2 \mathrm{wt} \%$ & $0.05 \mathrm{wt} \%$ & $0.1 \mathrm{wt} \%$
\end{tabular}

Table 4 Low frequency absorbing layer

\begin{tabular}{lllll}
\hline Serial Number & L1 & L2 & L3 & L4 \\
\hline CF Length & $2 \mathrm{~mm}$ & $2 \mathrm{~mm}$ & $3 \mathrm{~mm}$ & $3 \mathrm{~mm}$ \\
CF Content & $0.2 \mathrm{wt} \%$ & $0.3 \mathrm{wt} \%$ & $0.05 \mathrm{wt} \%$ & $0.1 \mathrm{wt} \%$
\end{tabular}

thickness of high frequency absorbing layers, absorbing properties keep decreasing in the C-band. However, in both the $\mathrm{X}$-band and the Ku-band, it is strengthened and a new

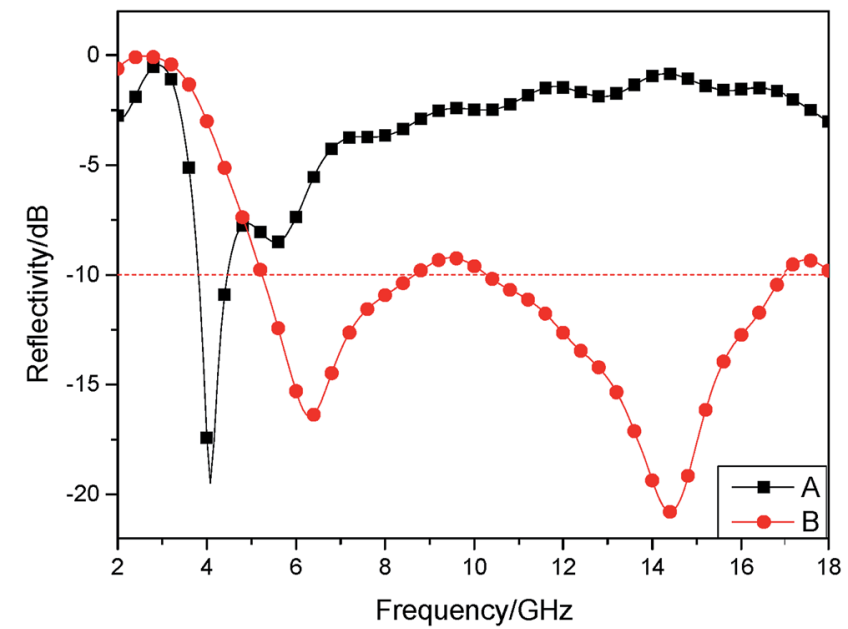

Fig. 10 Reflectivity of four-layer CFPURAC with different absorbing layer sequence. absorbing peak appears; when high frequency matching thickness is enlarged further, absorbing properties get lower. At the same time, absorbing peaks move to low frequency in the $\mathrm{X}$ band and the Ku-band. In X-band and Ku-band, part of microwave was reflected back into the air by the high frequency absorbing layer, the other part penetrated into the coating and reflected by the low frequency absorbing. The microwaves reflected by high frequency absorbing layer and low frequency absorbing layer could attain destructive interference and achieve effective microwave absorption with an appropriate high frequency matching thickness.

Fig. 12(a) indicates that coating absorbing property is the best when using $\mathrm{H} 1$ as high frequency absorbing layer, which has a matching thickness of $2 \mathrm{~mm}$. And reflectivity is lower than $-10 \mathrm{~dB}$ at both 5.3 to $8.6 \mathrm{GHz}$ and 10.3 to $16.9 \mathrm{GHz}$. The effective absorbing bandwidth reaches 9.9 GHz. Fig. 12(b) shows that coating absorbing property is the best when using $\mathrm{H} 2$ as high frequency absorbing layer, which has a matching thickness of $2 \mathrm{~mm}$. And reflectivity is lower than $-10 \mathrm{~dB}$ at both 5.2 to $6.5 \mathrm{GHz}$ and 9.8 to $13.9 \mathrm{GHz}$. The effective absorbing bandwidth reaches $5.4 \mathrm{GHz}$. Fig. 12(c) presents that coating absorbing property is the best when using $\mathrm{H} 3$ as high frequency

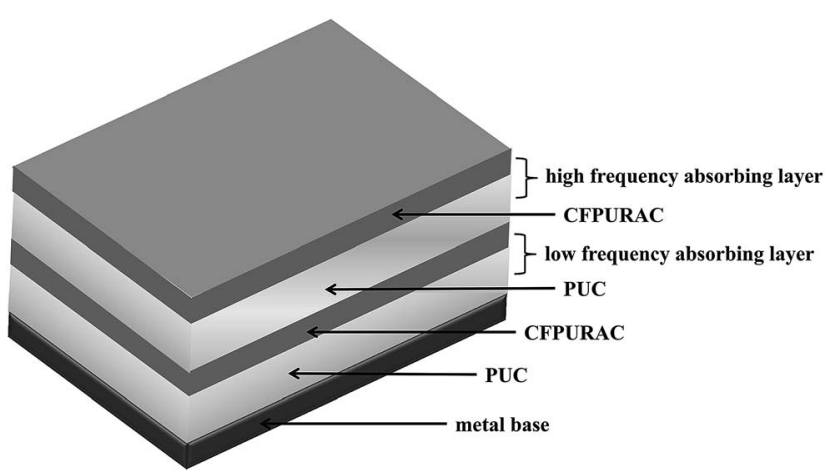

Fig. 11 Matching diagram of four-layer CFPURAC. 


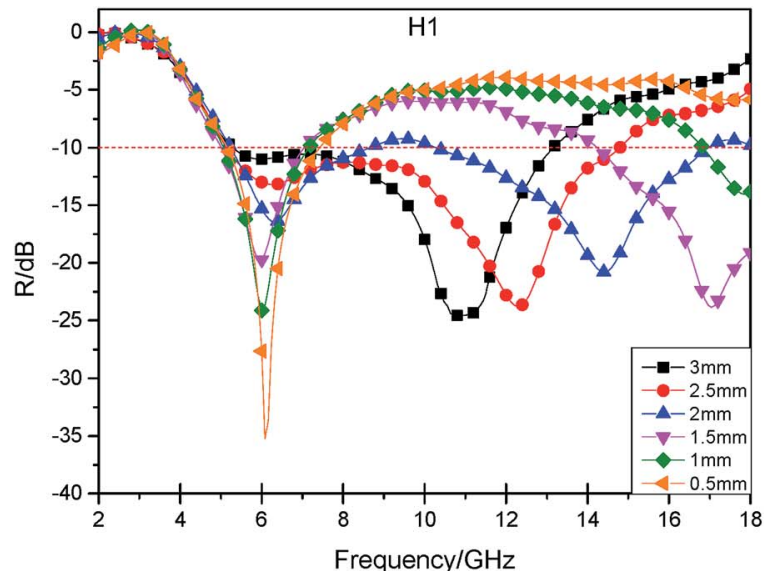

(a)

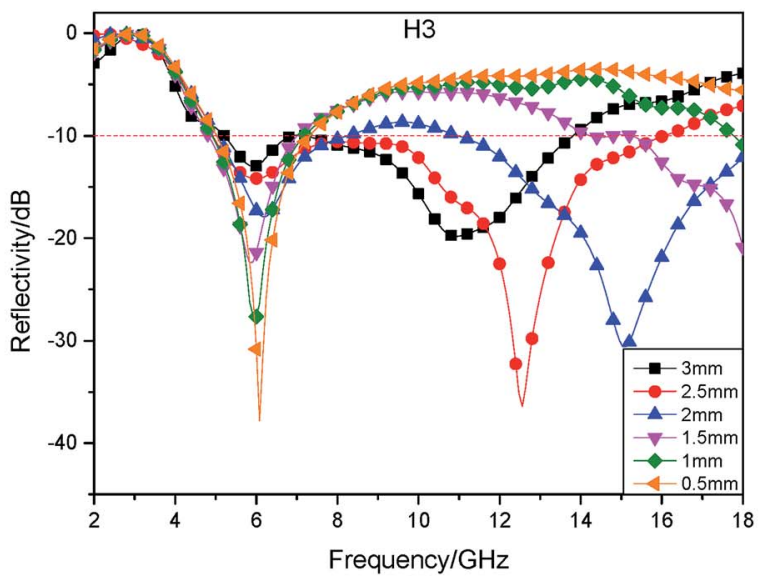

(c)

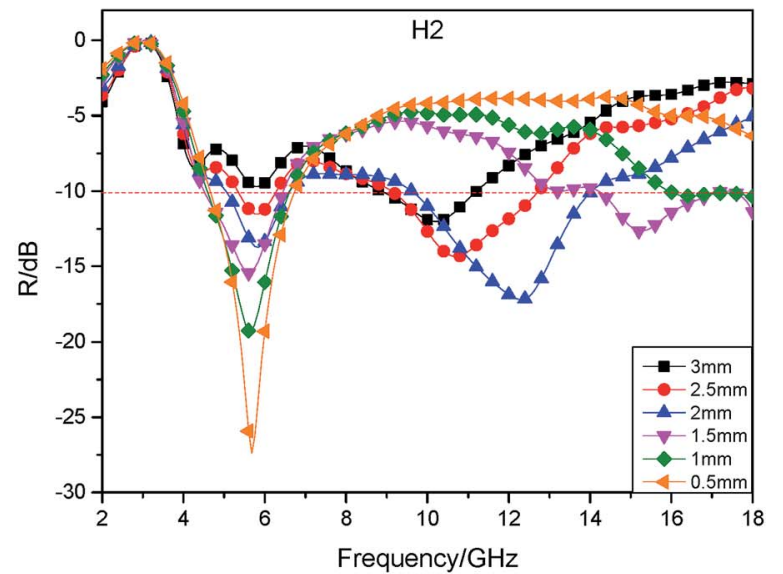

(b)

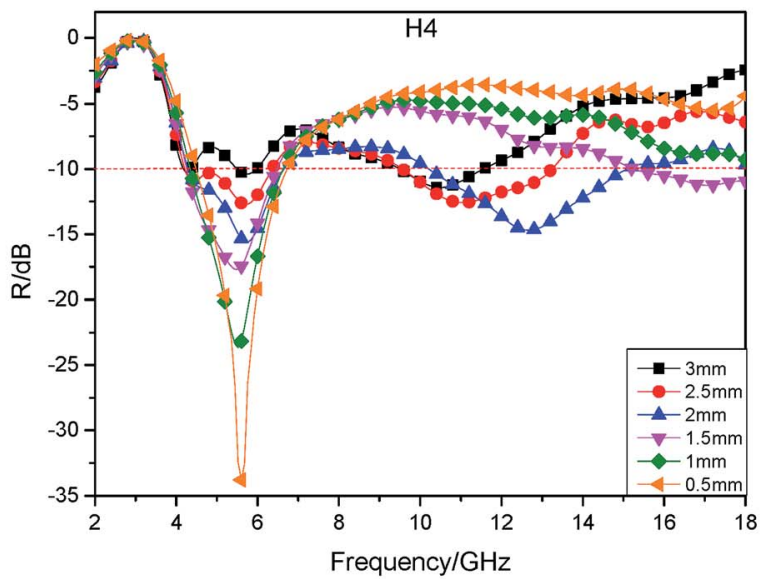

(d)

Fig. 12 Reflectivity of four-layer CFPURAC with different high frequency absorbing layers.

absorbing layer, which has a matching thickness of $2 \mathrm{~mm}$. And reflectivity is lower than $-10 \mathrm{~dB}$ at both 5 to $8.2 \mathrm{GHz}$ and 10 to $18 \mathrm{GHz}$. The effective absorbing bandwidth reaches $11.2 \mathrm{GHz}$. Fig. 12(d) indicates that coating absorbing property is the best when using $\mathrm{H} 4$ as high frequency absorbing layer, which has a matching thickness of $2 \mathrm{~mm}$. And reflectivity is lower than $-10 \mathrm{~dB}$ at both 4.3 to $6.5 \mathrm{GHz}$ and 10.2 to $15.1 \mathrm{GHz}$. The effective absorbing bandwidth reaches 7.1 GHz. Therefore, coating has the best overall absorbing property at 2 to $18 \mathrm{GHz}$ while using $\mathrm{H} 3$ as high frequency absorbing layer, which has a matching thickness of $2 \mathrm{~mm}$.

3.5.3 Impact of low frequency absorbing layer on absorbing property. The impact of different matching thicknesses of four low frequency absorbing layers including L1, L2, L3 and L4 on absorbing property is studied with $\mathrm{H} 3$ as high frequency absorbing layer (high frequency matching thickness is fixed as $2 \mathrm{~mm}$ ). Fig. 13 shows radar wave reflectivity of fourlayer CFPURAC with different low frequency matching thickness when L1, L2, L3 and L4 are regarded as low frequency absorbing layers. Seen from the Fig. 13, when low frequency matching thickness is $0.5 \mathrm{~mm}$, coating has a certain absorbing property in the $\mathrm{X}$-band and the Ku-band, but it is not functional in the S-band and the C-band; as low frequency matching thickness enlarges, radar wave reflectivity decreases at 2 to 18 $\mathrm{GHz}$ variously; to further increase low frequency matching thickness, the effective absorbing frequency band extends to low frequency continuously, but radar wave reflectivity keeps growing in the X-band; in the case of an excessively big low frequency matching thickness, coating is not functional in the X-band. In S-band and C-band, most of microwave penetrated into the high frequency absorbing layer. Then, part of microwave was reflected by the high frequency absorbing layer, the else microwave penetrated into the low frequency absorbing layer and reflected by the metal base. The microwaves reflected by low frequency absorbing layer and metal base could attain destructive interference and achieve good microwave absorption with an appropriate low frequency matching thickness.

Fig. 13(a) indicates that coating absorbing property is the best when using L1 as low frequency absorbing layer, which has a matching thickness of $1.5 \mathrm{~mm}$. And reflectivity is lower than $-10 \mathrm{~dB}$ at 6.1 to $18 \mathrm{GHz}$. The effective absorbing bandwidth reaches 11.9 GHz. Fig. 13(b) shows that coating absorbing property is the best when using $\mathrm{L} 2$ as low frequency absorbing layer, which has a matching thickness of $1.5 \mathrm{~mm}$. And reflectivity is lower than $-10 \mathrm{~dB}$ at 5.9 to $18 \mathrm{GHz}$. The effective absorbing bandwidth reaches $12.1 \mathrm{GHz}$. Fig. 13(c) presents that 


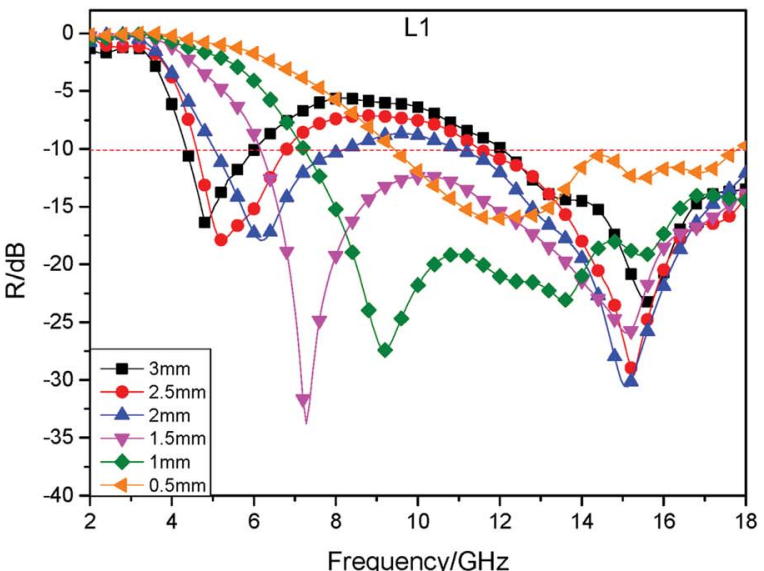

(a)

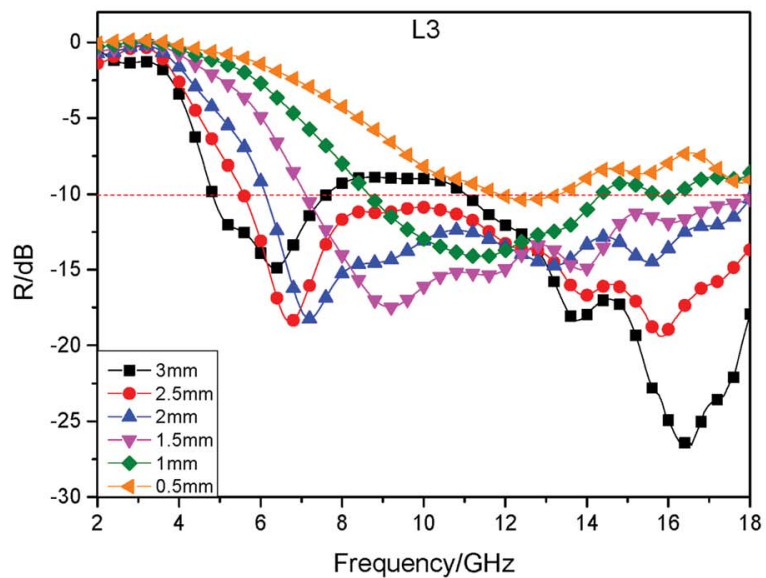

(c)

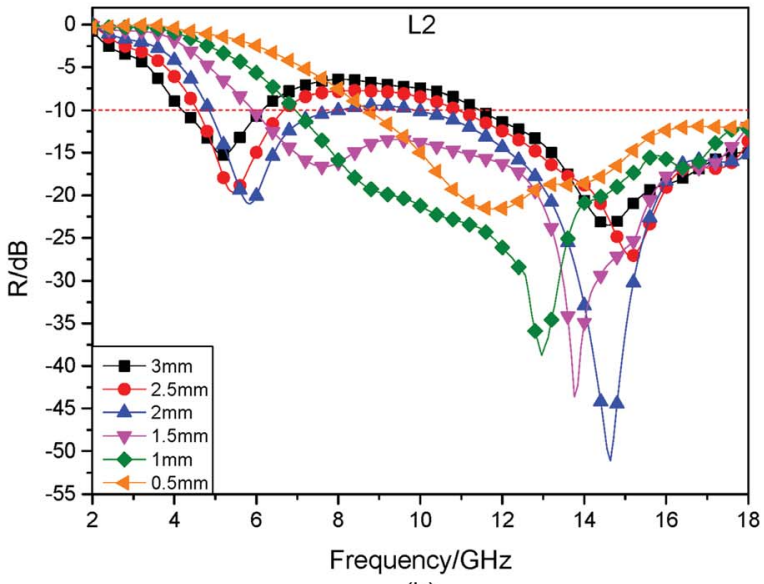

(b)

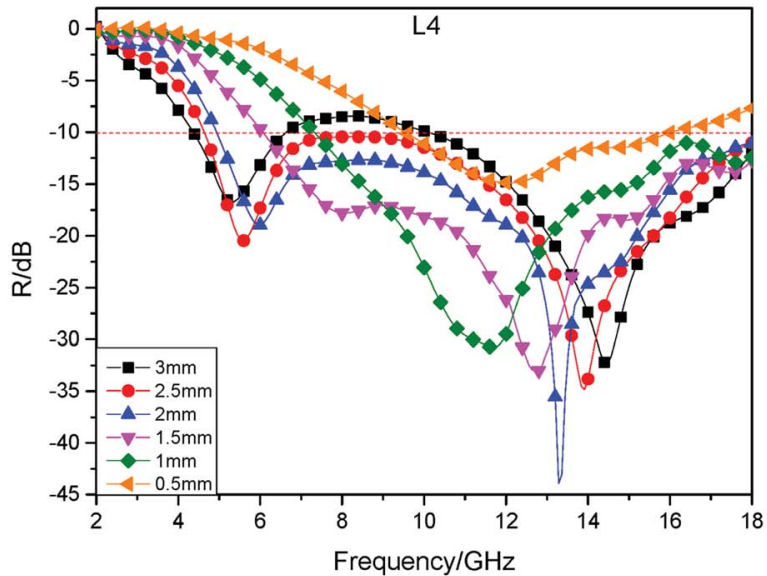

(d)

Fig. 13 Reflectivity of four-layer CFPURAC with different low frequency absorbing layers.

coating absorbing property is the best when using L3 as low frequency absorbing layer, which has a matching thickness of $2.5 \mathrm{~mm}$. And reflectivity is lower than $-10 \mathrm{~dB}$ at 5.6 to $18 \mathrm{GHz}$. The effective absorbing bandwidth reaches $12.4 \mathrm{GHz}$. Fig. 13(d) indicates that coating absorbing property is the best when using L4 as low frequency absorbing layer, which has a matching thickness of $2.5 \mathrm{~mm}$. And reflectivity is lower than $-10 \mathrm{~dB}$ at 4.6 to $18 \mathrm{GHz}$. The effective absorbing bandwidth reaches $13.4 \mathrm{GHz}$. Therefore, coating has the best overall absorbing property at 2 to $18 \mathrm{GHz}$ while using L4 as low frequency absorbing layer, which has a matching thickness of $2 \mathrm{~mm}$. Then optimum matching proposal of four-layer matching CFPURAC is: $\mathrm{H} 3$ is used as high frequency absorbing layer with matching thickness of $2 \mathrm{~mm}$; L4 is used as low frequency absorbing layer with matching thickness of $2 \mathrm{~mm}$.

\section{Conclusion}

(1) Double-layer CFPURC is prepared with PUC as isolating layer to match CFPURC, in order to enhance absorbing property of CFPURC. By adjusting the length and the content of CF in the coating, the effective absorption of four-layer CFPURAC was achieved in the C-band, the X-band and the Ku-band.
(2) Four-layer CFPURC is prepared based on double-layer CFPURC. High frequency absorbing layer is in a high position while low frequency absorbing layer is in a low position. Absorbing property of high frequency absorbing layer in a high position and low frequency absorbing layer in a low position is much better than that of high frequency absorbing layer in a low position and low frequency absorbing layer in a high position.

(3) The optimum matching proposal of four-layer CFPURC are, from top to bottom, CFPURAC with thickness of $0.5 \mathrm{~mm}$ and $0.05 \mathrm{wt} \% 2 \mathrm{~mm} \mathrm{CF}$, PUC with thickness of $2 \mathrm{~mm}$, CFPURAC with thickness of $0.5 \mathrm{~mm}$ and $0.1 \mathrm{wt} \% 3 \mathrm{~mm} \mathrm{CF}$, PUC with thickness of $2 \mathrm{~mm}$.

\section{Conflicts of interest}

There are no conflicts to declare.

\section{References}

1 G. S. Bae and Y. K. Che, Microw. Opt. Technol. Lett., 2014, 56(8), 1907-1910.

2 Z. P. Deng, Z. H. Liu, G. Z. Zhou and H. Zhang, J. Funct. Biomater., 2012, 43, 335-338. 
3 D. G. Holtby, K. L. Ford, and B. Chambers, IET Radar Sonar \& Navigation, 2011, vol. 5, 4, pp. 483-488.

4 M. Tehrani, A. Y. Boroujeni, T. B. Hartman, T. P. Haugh, S. W. Case and M. S. Al-Haik, Compos. Sci. Technol., 2013, 75(2), 42-48.

5 K. Zhang, G. Zhang, B. Liu, X. Wang, S. Long and J. Yang, Compos. Sci. Technol., 2014, 98(16), 57-63.

6 S. Rahmanian, A. R. Suraya, M. A. Shazed, R. Zahari and E. S. Zainudin, Mater. Des., 2014, 60, 34-40.

7 T. C. Zou, N. Q. Zhao and C. S. Shi, J. Funct. Mater. Devices, 2007, 13(1), 54.

8 T. Zou, N. Zhao, C. Shi and J. Li, Bull. Mater. Sci., 2011, 34(1), 75-79.

9 Y. Wang, A. Shah, H. Huang, F. Xue, L. Zhang, X. Dong and L. Zhang, Chin. J. Mater. Res., 2015, 29(2), 81-87.

10 Y. Liu and C. Qiang, Bull. Mater. Sci., 2015, 38(7), 1673-1678.
11 Z. Wang, K. Li, C. Wang and J. Xie, J. Chin. Ceram. Soc., 2011, 39(1), 69-74.

12 F. C. Seman, and R. Cahill, $R f$ and Microwave Conference, IEEE, 2012, pp. 373-376.

13 M. Cao, R. Qin, C. Qiu and J. Zhu, Mater. Des., 2003, 24(5), 391-396.

14 M. S. Cao, W. L. Song, Z. L. Hou, B. Wen and J. Yuan, Carbon, 2010, 48(3), 788-796.

15 G. Shen, Z. Xu and Y. Li, J. Magn. Magn. Mater., 2006, 301(2), 325-330.

16 W. L. Song, M. S. Cao, Z. L. Hou, X. Y. Fang, X. L. Shi and J. Yuan, Appl. Phys. Lett., 2009, 94(23), 233110.

17 W. Liu, C. Wang, and Y. Qi, Saf EMC, 2011, pp. 13-14.

18 B. Wen, M. S. Cao, Z. L. Hou, W. L. Song, L. Zhang, M. M. Lu and J. Yuan, Carbon, 2013, 65, 124-139. 